\title{
3-D Micro-Scale Machining Implementation
}

Federal Manufacturing \& Technologies

Christopher L. Boucher

KCP-613-8521

Published October 2008

\section{Final Report}

Approved for public release; distribution is unlimited.

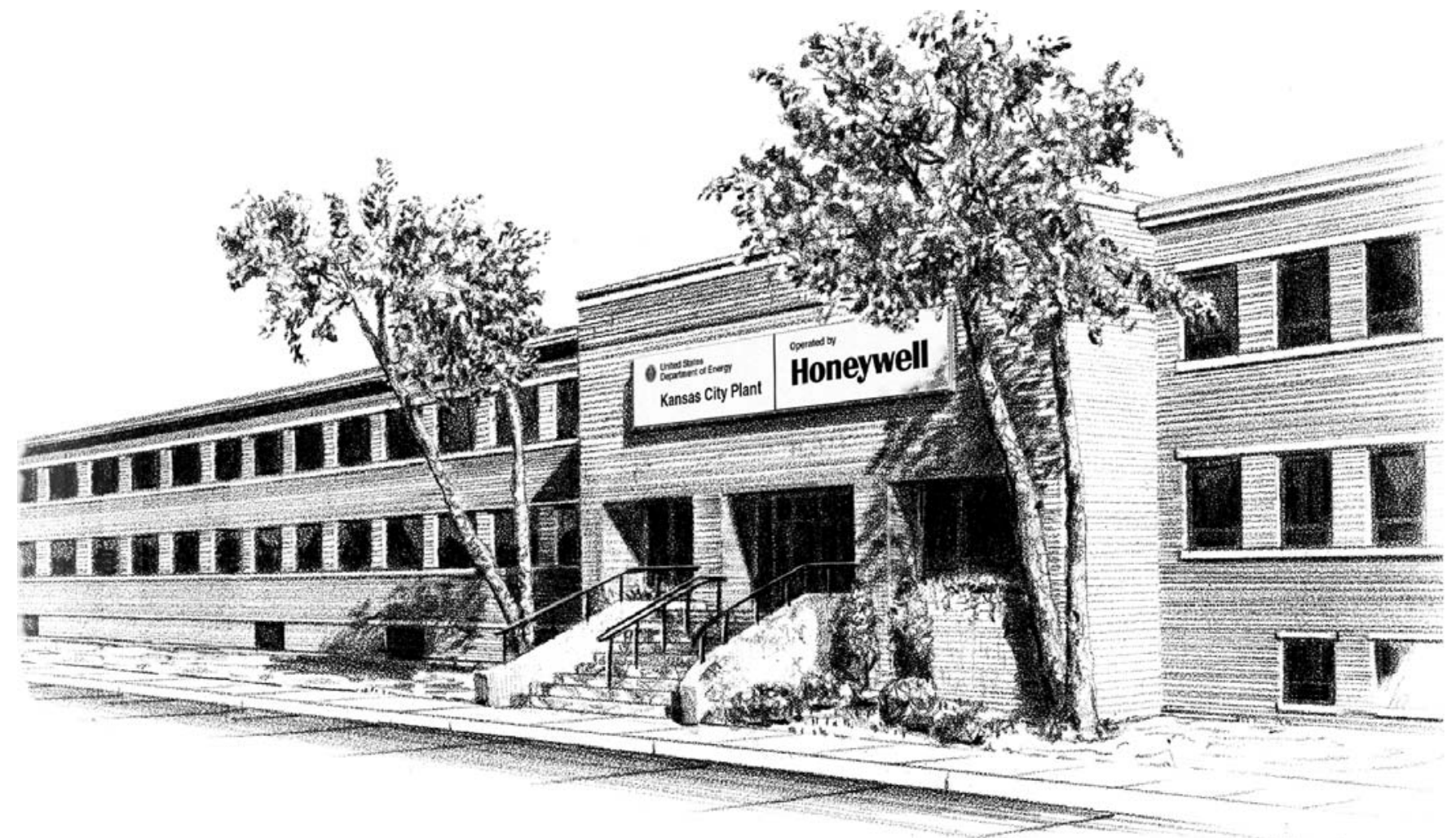

Prepared under prime contract DE-ACO4-01AL66850 for the

United States Department of Energy 


\section{DISCLAIMER}

This report was prepared as an account of work sponsored by an agency of the United States Government. Neither the United States Government nor any agency thereof, nor any of their employees, makes any warranty, express or implied, or assumes any legal liability or responsibility for the accuracy, completeness, or usefulness of any information, apparatus, product, or process disclosed, or represents that its use would not infringe privately owned rights. Reference herein to any specific commercial product, process or service by trade names, trademark, manufacturer, or otherwise, does not necessarily constitute or imply its endorsement, recommendation or favoring by the United States Government or any agency thereof. The views and opinions of authors expressed herein do not necessarily state or reflect those of the United States Government or any agency thereof.

All data prepared, analyzed and presented has been developed in a specific context of work and was prepared for internal evaluation and use pursuant to that work authorized under the reference contract. Reference herein to any specific commercial product, process or service by trade name, trademark, manufacturer, or otherwise, does not necessarily constitute or imply its endorsement, recommendation or favoring by the United States Government, any agency thereof or Honeywell Federal Manufacturing \& Technologies, LLC.

Printed in the United States of America.

This report has been reproduced from the best available copy.

Available to DOE and DOE contractors from the Office of Scientific and Technical Information, P.O. Box 62, Oak Ridge, Tennessee 37831; prices available from (865) 576-8401, FTS 626-8401.

Available to the public from the National Technical Information Service, U.S. Department of Commerce, 5285 Port Royal, Rd., Springfield, Virginia 22161, (703) 487-4650.

A prime contractor with the United States Department of Energy under Contract Number DE-AC04-O1AL66850

\author{
Honeywell Federal Manufacturing \& Technologies \\ P.O. Box 419159 \\ Kansas City, Missouri, 64141-6159
}




\section{Honeywell}

KCP-613-8521

Distribution Category UC-42

Approved for public release; distribution is unlimited.

3-D Micro-Scale Machining Implementation

Christopher L. Boucher

Published October 2008

Final Report

Christopher L. Boucher, Project Leader 



\section{Contents}

Section Page

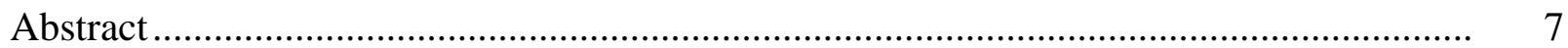

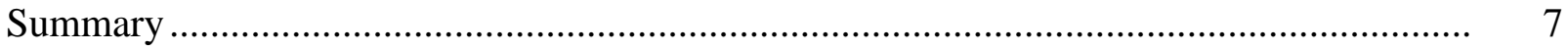

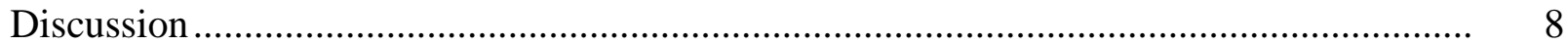

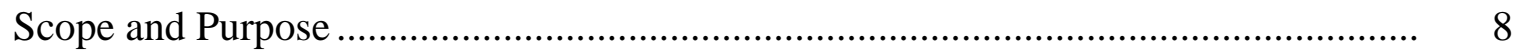

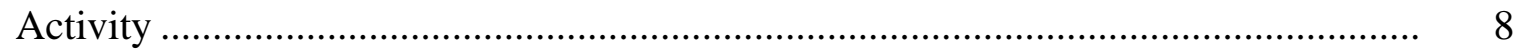

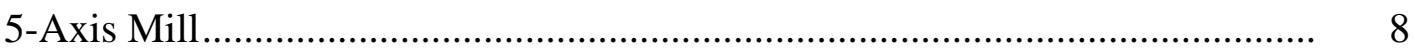

Lathe and Wire EDM..................................................................... 10

Micro-Machining Vendors.................................................................... 13

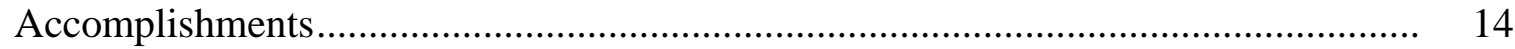

Appendices

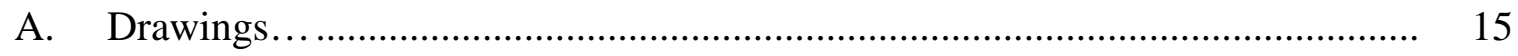

B. Inspection Data for 2 Typical Lathe Wire EDM Test Parts............................. 18 


\section{Illustrations}

Figure Page

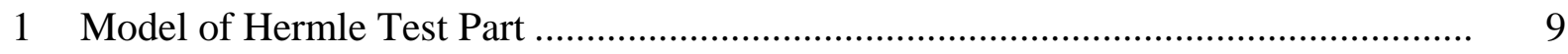

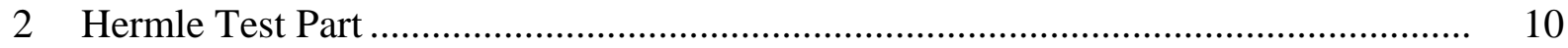

3 Model of Lathe and Wire EDM Test Part............................................................... 11

4 Example of Wire Touch Mark .......................................................................... 12

$5 \quad$ Levin Lathe and Charmilles Wire EDM Test Part................................................... 13 


\begin{abstract}
The KCP investigated milling, turning, and wire EDMing features at a micro-scale using existing equipment to find the limitations and hindrances to producing future designs.
\end{abstract}

\title{
Summary
}

The Kansas City Plant (KCP) had an interest in machining smaller parts than those currently in production. The need for the smaller scale became apparent as the designs sent to KCP began to steadily scale down. This project investigated micro-sized 3dimensional features using the Hermle C600U and the Levin Micro-Turn CNC Lathe. It also investigated adding Wire EDM features to 3-dimensional turned parts.

The Hermle machined a test part with features designed to test the machine's ability to mill a contour. The part had hemispherical features that stepped down in size from .030" down to .001” as well as the reverse (negative features) from .030” down to .015”. The part was milled using a diamond coated ball end mill.

The Levin Lathe was used to turn contours with stainless steel diameters as small as .010 ” and radii as small as .0025”. Tooling used on the Levin had a .001” nose radius. After the turning work was completed, the parts were taken to the Charmilles Robofil 4020SI and cut using the .004” diameter wire.

Attempts were made to establish a relationship with a micro-machining vendor, but the industry still needs to mature before there is an adequate pool of micro-machining houses in the United States.

The project allowed engineering staff to investigate features of interest for future designs as well as test some of the machines currently in house. The results of machining the parts using existing equipment showed where the KCP is lacking in capability and will drive decisions on future capital equipment procurements. 


\section{Discussion}

\section{Scope and Purpose}

The Kansas City Plant (KCP) had an interest in machining smaller parts than those currently in production. The need for the smaller scale became apparent as the designs sent to the KCP began to steadily scale down. Parts are getting smaller as raw material and transportation costs are rising quickly.

Designs for smaller parts have been made possible through the abundance of computing power that is available at a minimal cost. Finite element analysis has allowed designers to model parts that are smaller and more complex than in the past, and it has also allowed them the ability to electronically validate functionality.

At the same time, CNC machines and controllers have advanced in the past 20 years and now offer extremely tight control with very repeatable results. Newer machines on the market advertise machining centers that will hold tolerances in the nanometers.

The KCP has been keeping an eye on the machine tool market, but also chose to investigate what the machines currently used for production are capable of doing. This project builds upon past projects investigating the capability of the Wire EDM. The EDM is capable of very fine features (cutting wire of .001" is available) and extremely tight tolerances (.000039" or better for production), but it is limited to 2-dimensional features.

This project investigated micro-sized 3-dimensional features using the Hermle C600U, the Levin Micro-Turn CNC Lathe, as well as adding Wire EDM features to 3dimensional turned parts.

\section{Activity}

\section{$\underline{\text { 5-Axis Mill }}$}

The Hermle C600U is a relatively new machine to the KCP. Several were purchased for production and serve as general milling machines. They are 5-axis milling centers with a 12,000 RPM spindle. The part machined was a test part with features designed to test the machine's ability to mill a contour. The part had hemispherical features that stepped down in size from .030" to .001" as well as the reverse (negative features) from .030" down to .015". Tooling used was diamond coated micro grain carbide from Harvey Tool. The test part was finish machined with a .015" ball end mill. 


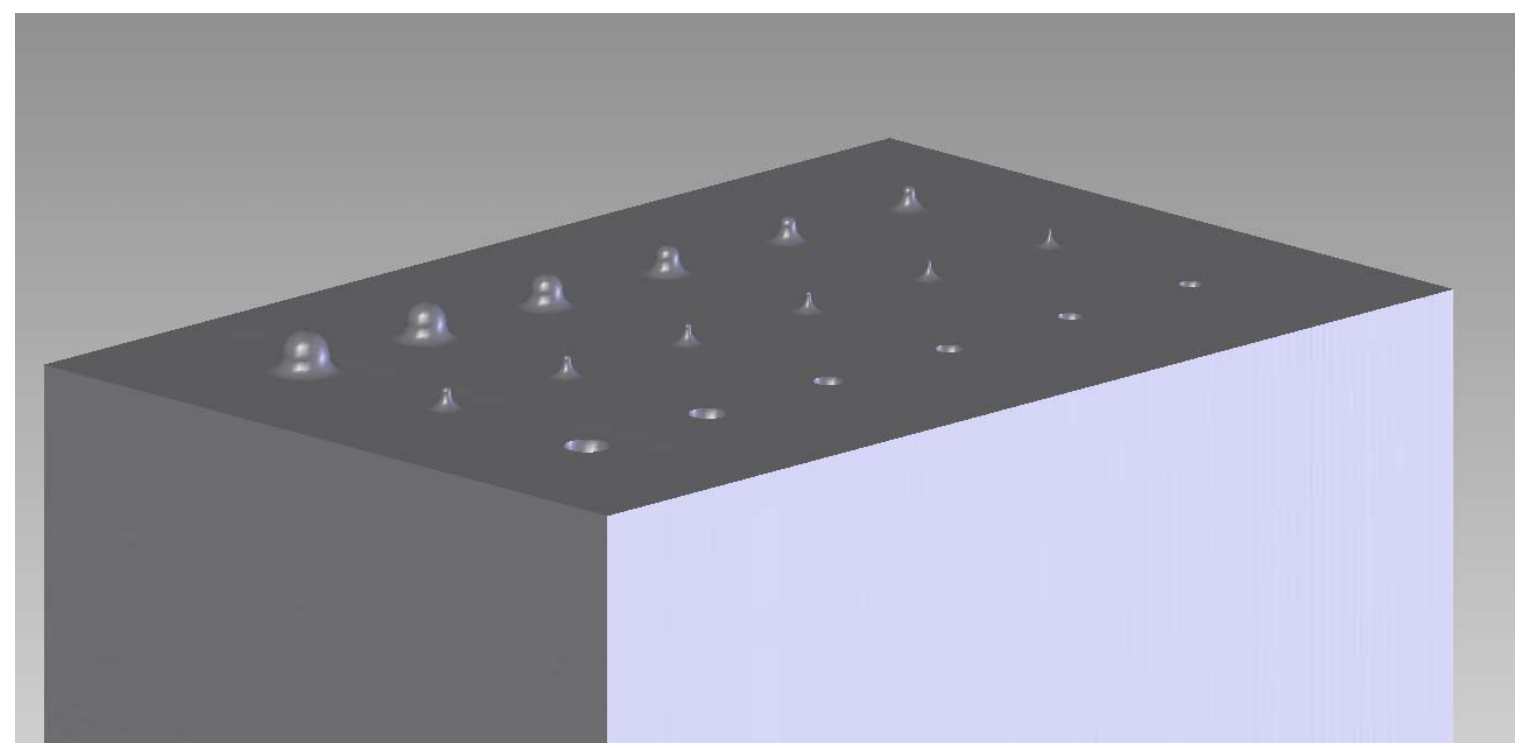

Figure 1. Model of Hermle Test Part

The first problem encountered was the size of the part program. The tool path needed for the ball end mill created a part program over $4 \mathrm{Mb}$ in size. The Hermles were in the process of being networked, but until that was finished the team was limited to transferring the part program using 3.5" floppy disks. The program needed to be split into three part programs and run sequentially to machine the entire part.

The second problem was setting up the tooling for the machine. The Hermle has a laser tool setter to pick up the length of the cutting tool. A program had been written to automatically bring the tools out one at a time and set the length offsets using the tool setter. It was found when the first part was machined that the length offsets were not correct. The laser could not accurately pick up the very small diameter tools and each of those tools had to be manually tweaked in. This process required a very light touch as tools this size cannot withstand much force without breaking.

Once the tools were set and the programs loaded, the parts ran very well. Some adjusting of the diameter compensation was needed as the parts initially ran .0002"-.0003" undersized. Overall, the Hermle had the precision and repeatability (across 4 complete parts) to machine the features within .0001" down to .004" and with slightly less accuracy down to .001". Below .004", the material did not have the stiffness required to prevent deformation during the cutting process. Material selection needs to be further investigated as many material characteristics will determine suitability for microapplications. A sample part is shown in Figure 2. 


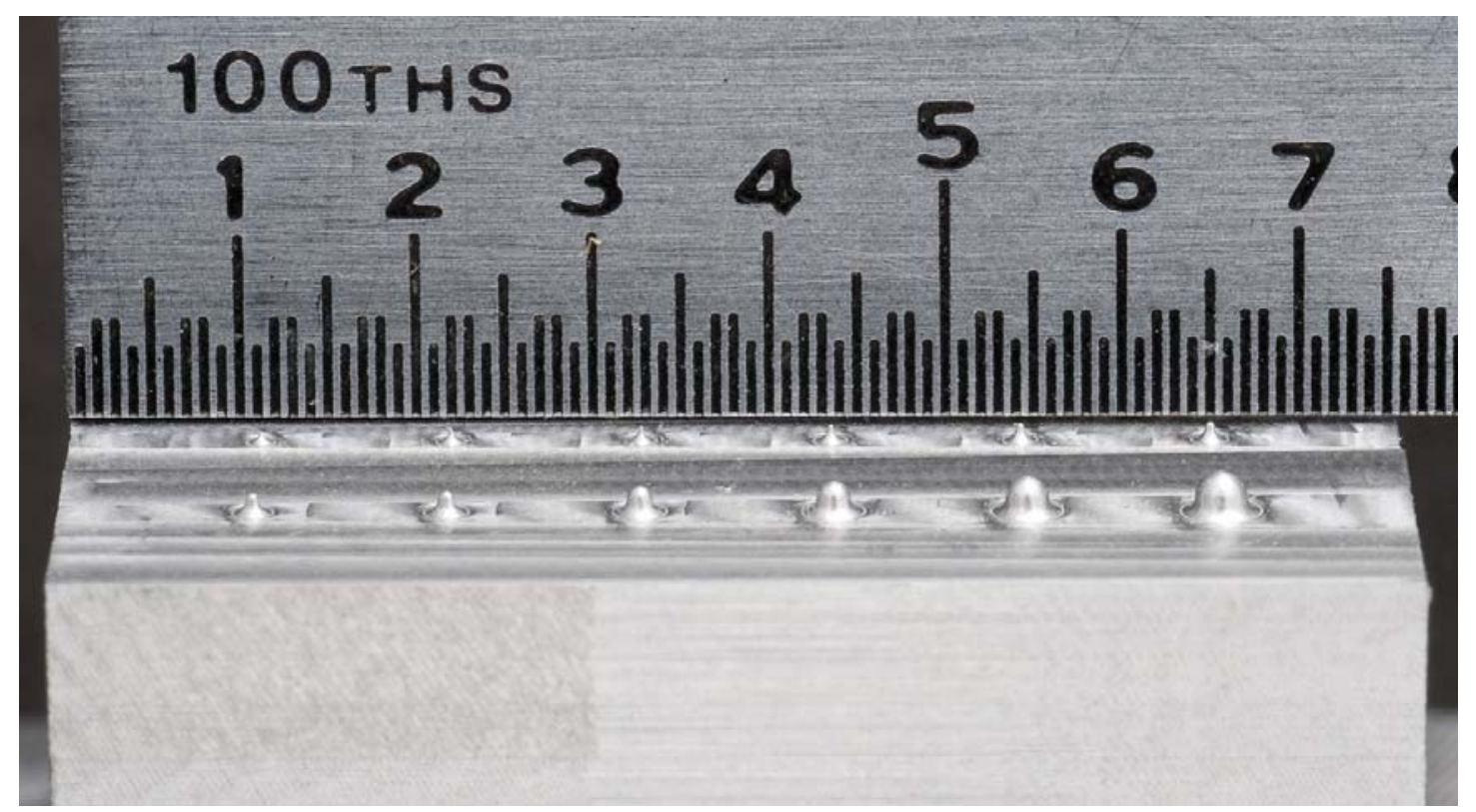

Figure 2. Hermle Test Part

\section{Lathe and Wire EDM}

The Levin Micro-Turn CNC Lathe is an established machine in the Mini Shop a KCP department Model Shop. It is equipped with a 15,000 RPM spindle and a 4 position tool holder. The machine has been used to consistently drill .002” holes. Programming for the machine is done in MasterCam. For this project, contours with diameters as small as .010 ” were turned in stainless steel with radii as small as .0025”. Tooling used on the Levin had a .001” nose radius.

Dimensional accuracy on the Levin was exceptional; however, some problems were experienced with the Levin's ability to move both axes simultaneously. The fillets were not consistent. Inspection data for two typical parts is given in Appendix B. 


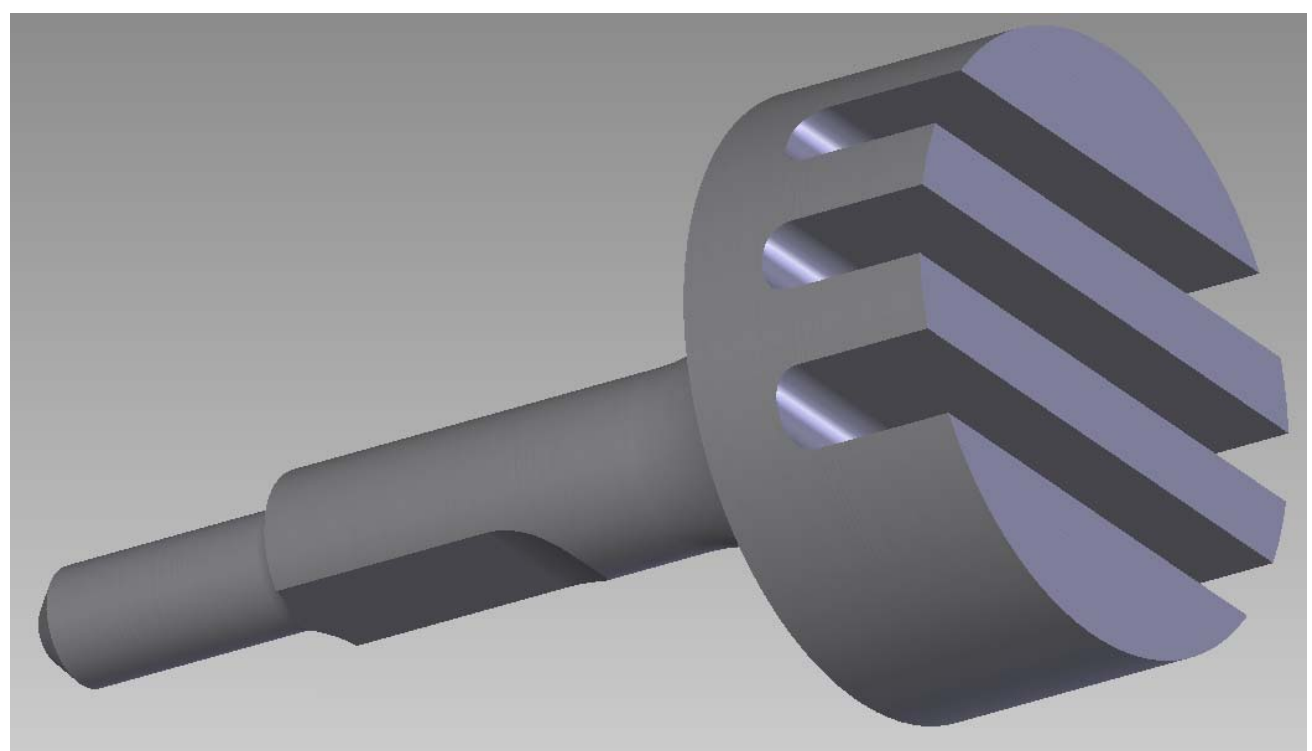

Figure 3. Model of Lathe and Wire EDM Test Part

After the turning work was completed, the parts were taken to the Charmilles Robofil 4020SI. The Charmilles is used as a model making Wire EDM and is setup for .010" and .004 " wire diameter. The machine is capable of holding +/- .000039" and regularly meets this specification on production parts. For this study, work holding became the main issue. The size of the parts required a custom fixture to hold the part at the base of the head on the .0181 " radius.

An unexpected problem occurred when the wire was used to pick up the edge of the part. It is common practice to touch the edge of the part with the wire to set " 0 " for the controller. On a production sized part, it was not noticed that the wire leaves a nick in the side of the part. The small amount of current used to check for continuity was enough to leave a noticeable mark on the micro-sized part and is shown in Figure 4. 


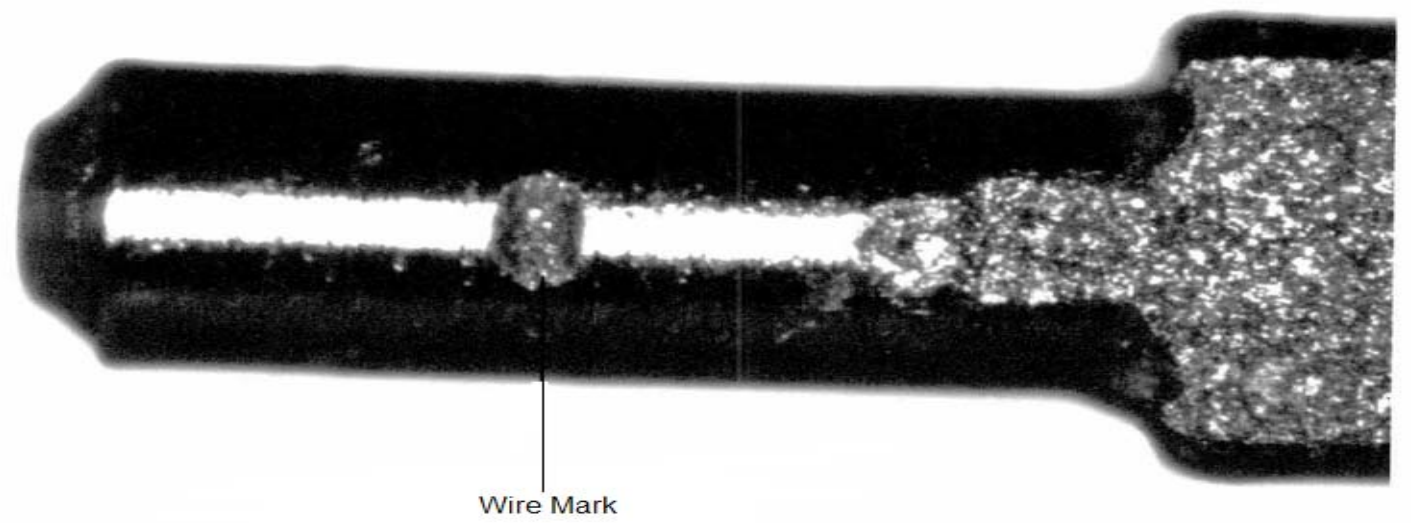

Figure 4. Example of Wire Touch Mark

This problem can be overcome by leaving stock past the end of the part for the EDM to touch off. The excess material can then be cut off as part of the Wire EDM program. Stiffness of the material does not make a difference with the EDM as cutting forces are negligible; however, residual stress from prior machining operations needs to be addressed. With cold work, stainless steels will have a stressed external surface from plastic deformation. This cold work frequently causes problems on a larger scale and the problems were magnified as the size of the part decreased. In the case of the test part, the slotted end of the pin began to collapse. The sample part is shown in Figure 5 along with $.005 ”, .010 ”$, and .015” ball end mills. Work with the .005” end mill is still in progress. 


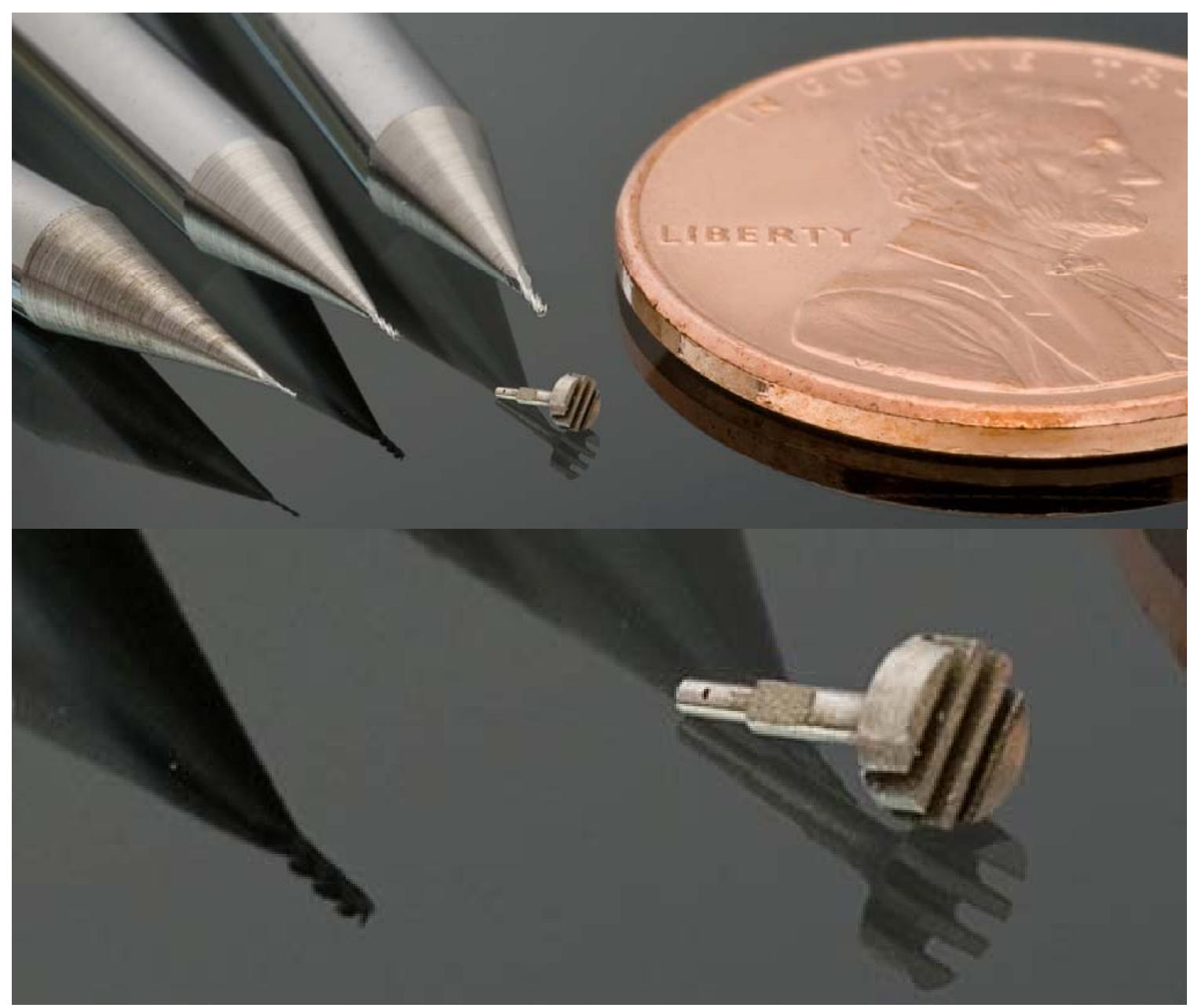

Figure 5. Levin Lathe and Charmilles Wire EDM Test Part

\section{Micro-Machining Vendors}

Several searches were performed to find micro-machining vendors throughout the United States. A couple of shops were found via the internet and contact was made via email and telephone. A sample part was drawn which included several features of interest to the team and sent to the vendors. None of the vendors contacted were willing to attempt the sample part. It was concluded that the micro-machining industry is still in its infancy and if the KCP wishes to machine features in the micro-sized range the technology must be developed in house. 


\section{Accomplishments}

The KCP investigated milled, turned, and wire EDMed features smaller than those currently used in production as well as attempted to establish a relationship with a micromachining vendor. Using the 5-Axis Hermle for the small features allowed engineering staff to investigate the capabilities of the machine as well as the limitations of its controller. It was found that material selection and stress relieving needs to be an integral part of the process when machining features on the micro-scale. The team found the limitations on program size for transferring to the Hermle C600U. It was also found that the laser tool setter on the Hermle is inadequate for tools that measure .015” and less.

On the Levin Lathe, the team found issues with the lathe's ability to turn contours using both axes simultaneously; however, the lathe was very capable of turning accurate diameters repeatedly. For the Wire EDM as a secondary operation, the team learned that extra material needed to be designed in and left for the EDM to Zero off of as well as extra material to hold on to. This will be included in reviews of future designs as part of the manufacturability study of the parts.

Attempts were made to establish a relationship with a micro-machining vendor, but the industry still needs to mature before there is an adequate pool of micro-machining houses in the United States.

Overall, the project allowed engineering staff to investigate features of interest for future designs as well as test some of the machines currently in house. The results of machining the parts using existing equipment showed where the KCP is lacking in capability and will drive decisions on future capital equipment procurements. 


\section{Appendix}

Appendix A: Drawings

(See the following page) 


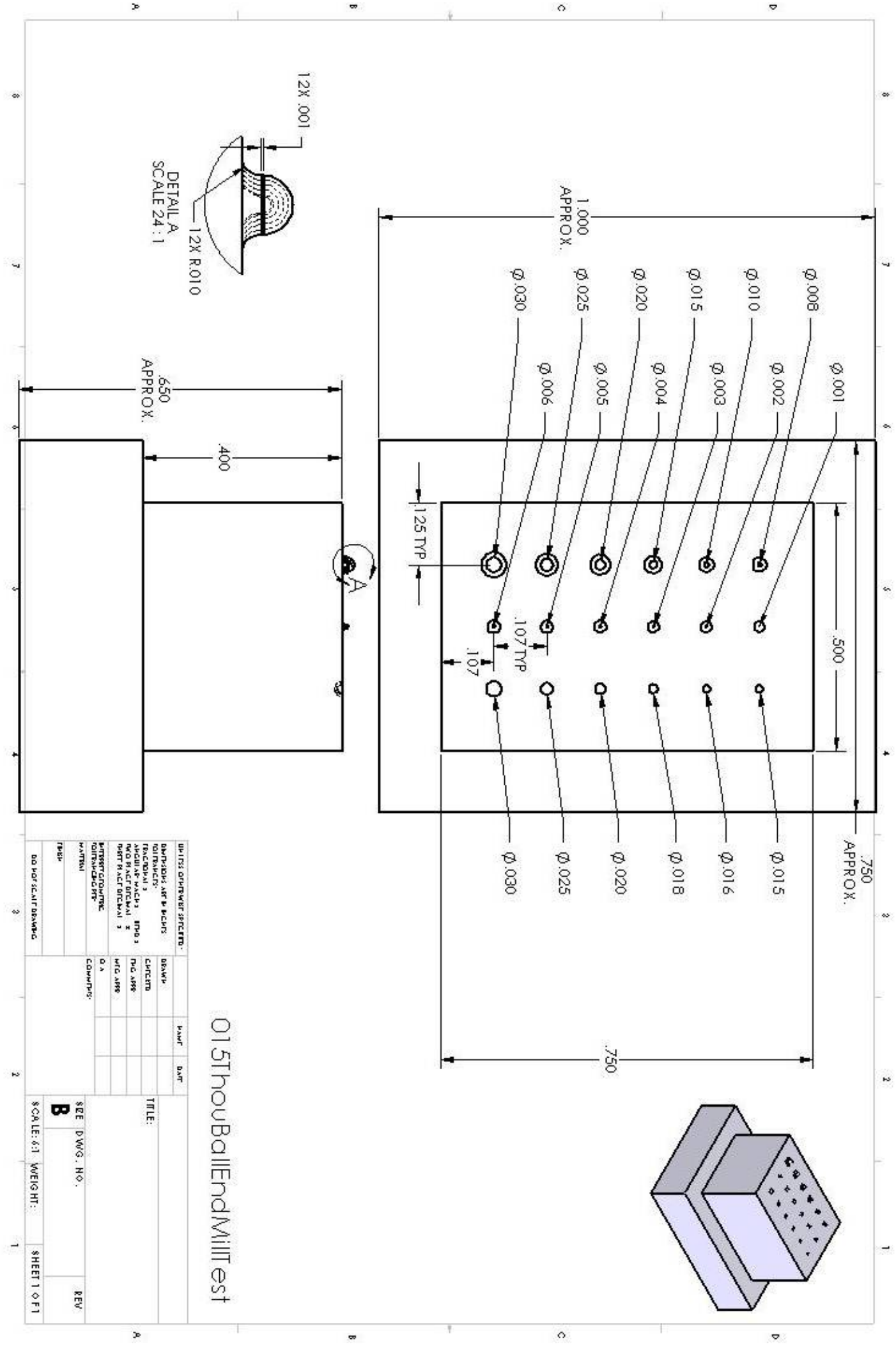




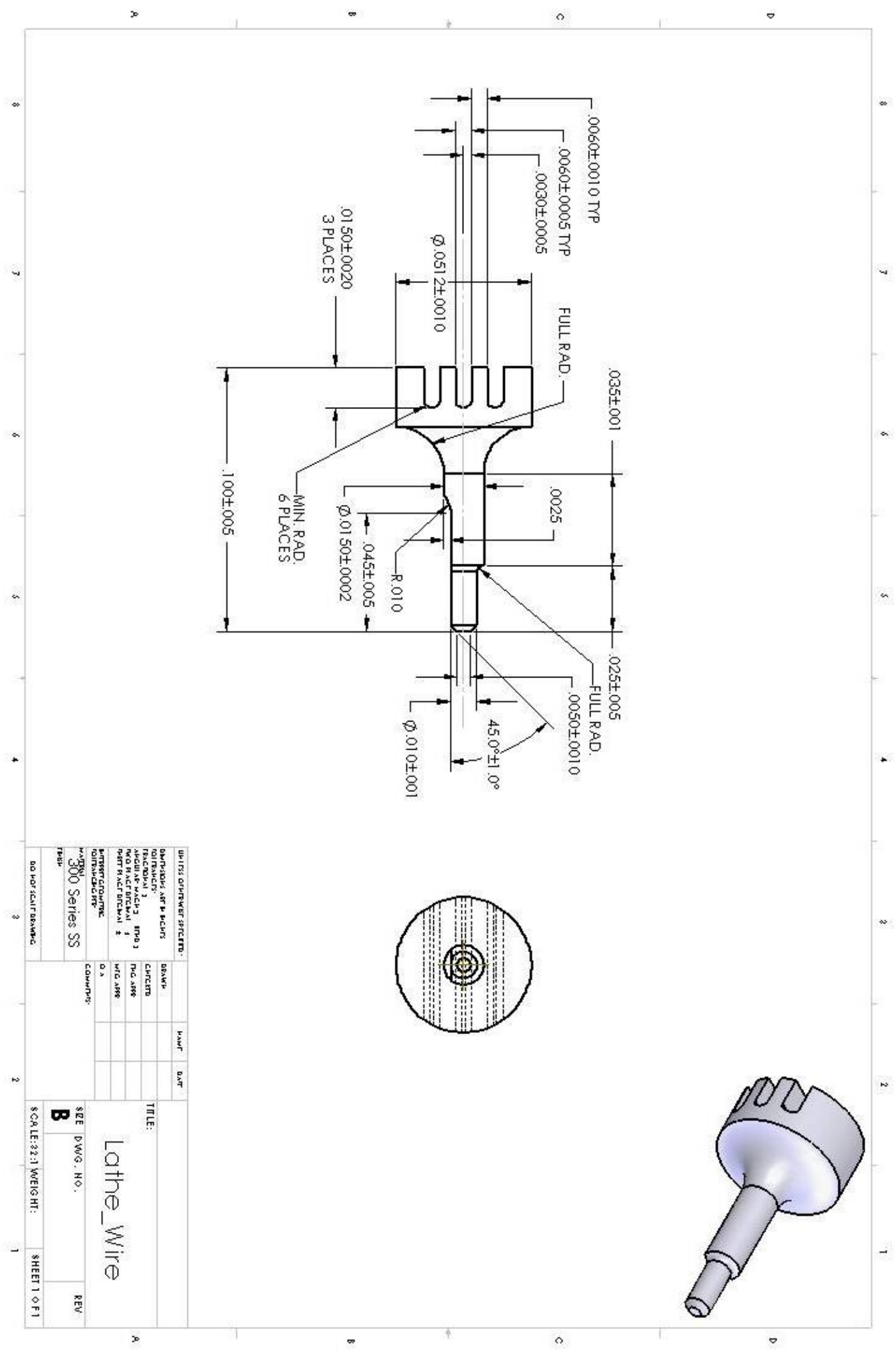


Appendix B: Inspection Data for 2 Typical Lathe Wire EDM Test Parts

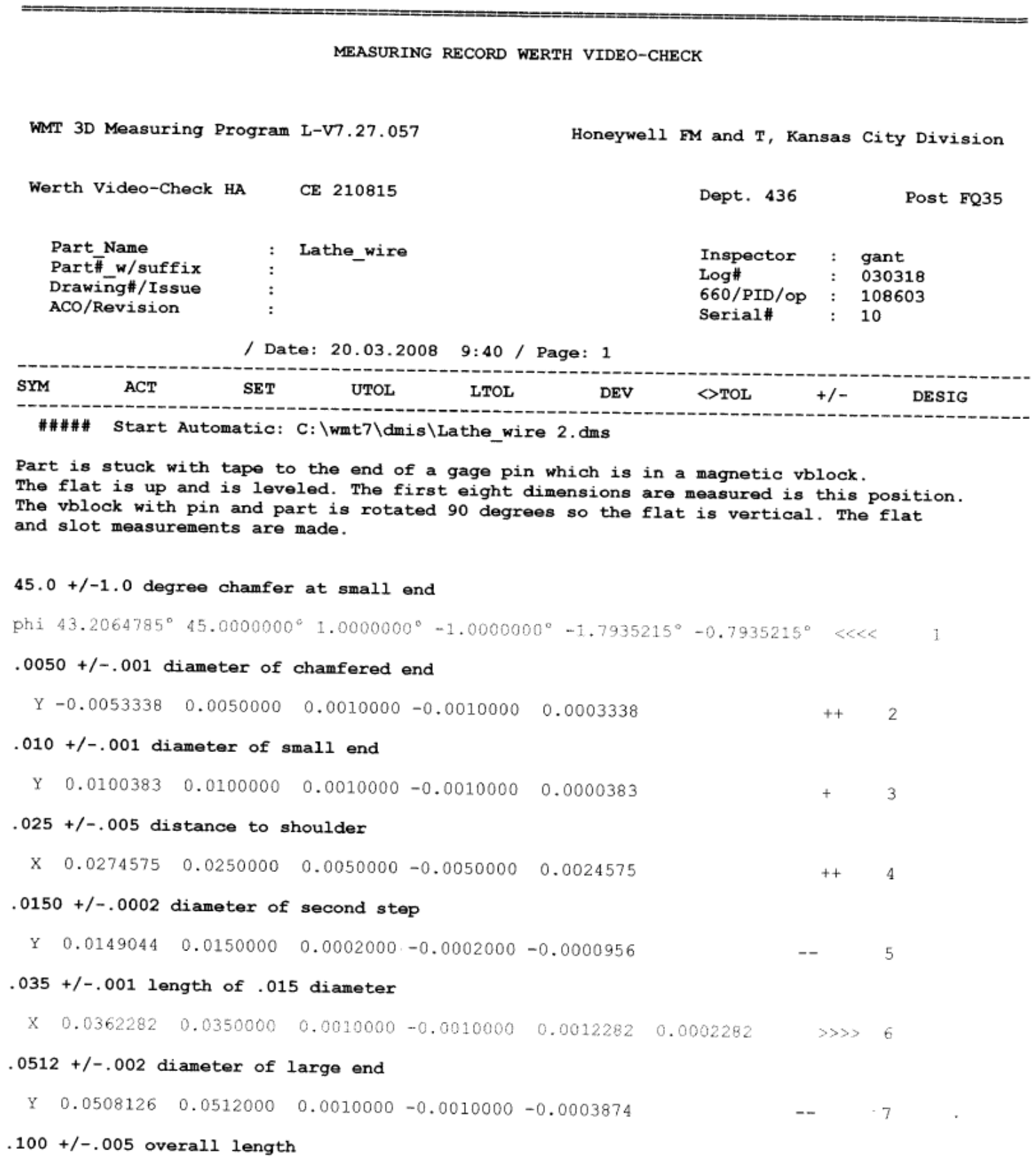


/ Date: 20.03.2008 9:40 / Page: 2

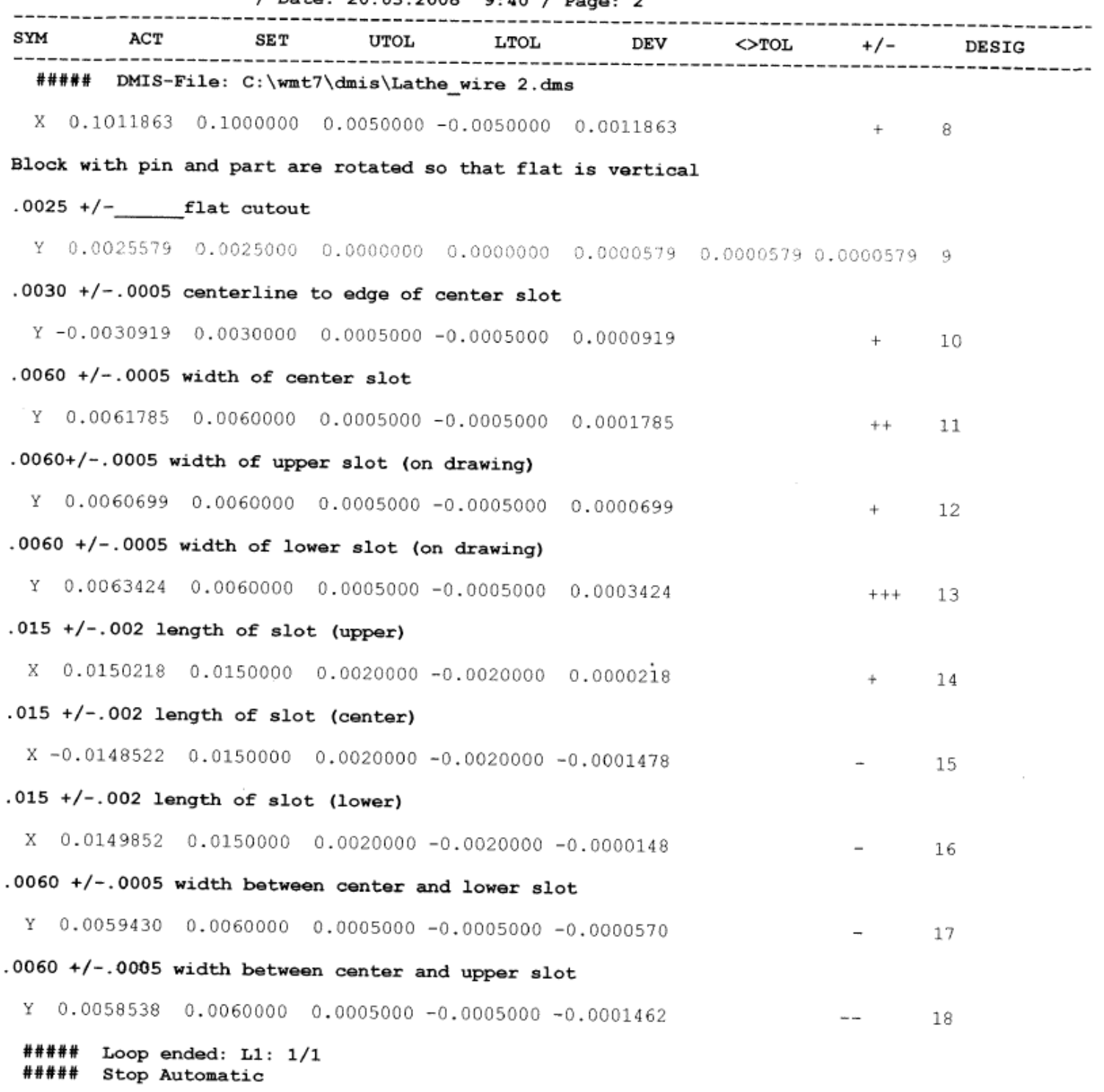


MEASURING RECORD WERTH VIDEO-CHECK

WMT 3D Measuring Program L-V7.27.057

Werth Video-Check HA

CE 210815

$\begin{array}{ll}\text { Part_Name } & : \text { Lathe_wire } \\ \text { Part\#_w/suffix } & : \\ \text { Drawing\#/Issue } & : \\ \text { ACO/Revision } & :\end{array}$

Honeywell FM and T, Kansas City Division

Dept. $436 \quad$ Post FQ35

/ Date: 20.03.2008 12:56/ Page: 1

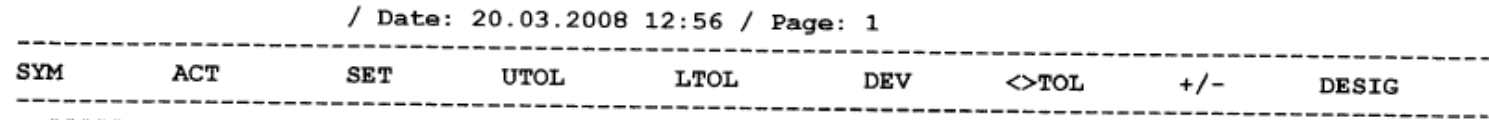

\#\#\#\# Start Automatic: C: \wmt7 \dmis \Lathe_wire 2.dms

Part is stuck with tape to the end of a gage pin which is in a magnetic vblock.

The flat is up and is leveled. The first eight dimensions are measured is this position.

The vblock with pin and part is rotated 90 degrees so the flat is vertical. The flat and slot measurements are made.

$45.0+/-1.0$ degree chamfer at small end

phi $47.6930245^{\circ} 45.0000000^{\circ} 1.0000000^{\circ}-1.0000000^{\circ} 2.6930245^{\circ} 1.6930245^{\circ} \quad>>>1$

$.0050+/-.001$ diameter of chamfered end

$\begin{array}{lllllll}Y-0.0050447 & 0.0050000 & 0.0010000 & -0.0010000 & 0.0000447 & +\end{array}$

$.010+/-.001$ diameter of small end

$\begin{array}{lllllll}Y & 0.0100008 & 0.0100000 & 0.0010000 & -0.0010000 & 0.0000008 & +\end{array}$

$.025+/-.005$ distance to shoulder

$\begin{array}{lllllllll}\text { X } & 0.0264609 & 0.0250000 & 0.0050000 & -0.0050000 & 0.0014609 & 4\end{array}$

$.0150+/-.0002$ diameter of second step

Y $\quad 0.0148644 \quad 0.0150000 \quad 0.0002000-0.0002000 \quad-0.0001356$

$.035+/-.001$ length of .015 diameter

$\begin{array}{llllllllll}X & 0.0374142 & 0.0350000 & 0.0010000 & -0.0010000 & 0.0024142 & 0.0014142 & >>> & 6\end{array}$

$.0512+/-.002$ diameter of large end

$\begin{array}{llllllll}\text { Y } & 0.0507570 & 0.0512000 & 0.0010000 & -0.0010000 & -0.0004430 & -\end{array}$

$.100+/-.005$ overall length 


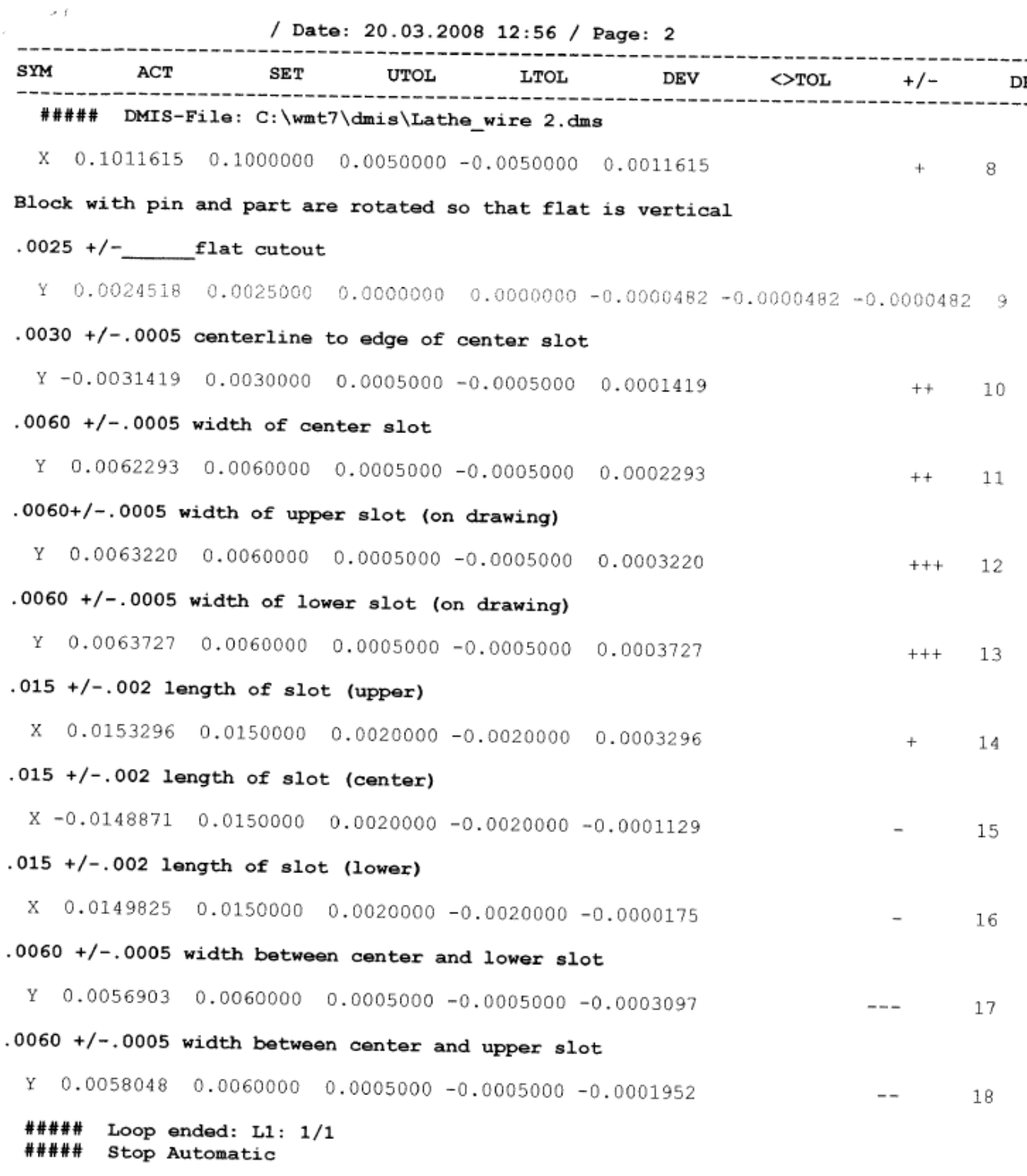

